\title{
Challenges Faced by Patients with Dyslipidemia and Systemic Arterial Hypertension in Brazil: A Design of the Patient Journey
}

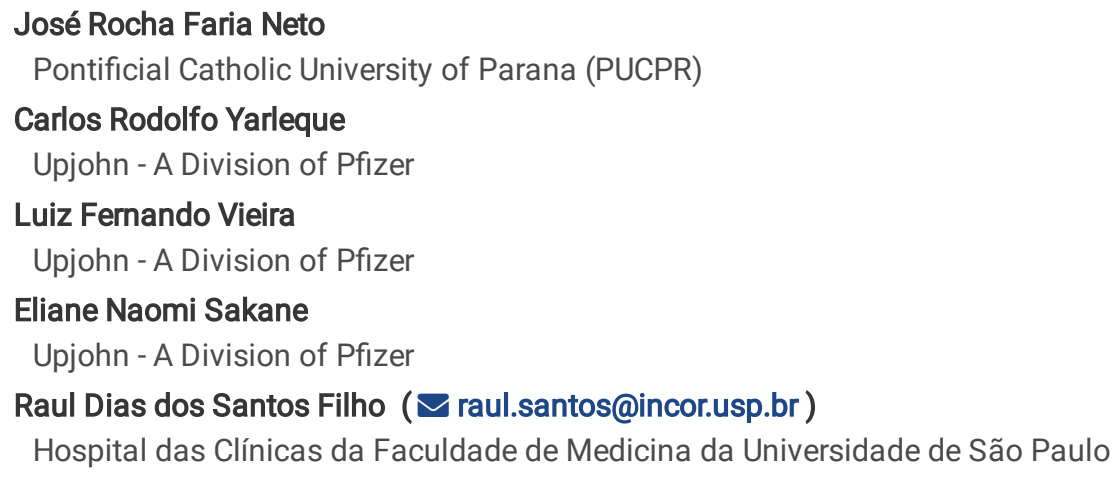

Keywords: Systemic arterial hypertension, dyslipidemia, patient journey, prevalence, diagnosis, treatment.

Posted Date: August 3rd, 2021

DOI: https://doi.org/10.21203/rs.3.rs-721586/v1

License: (c) (i) This work is licensed under a Creative Commons Attribution 4.0 International License. Read Full License 


\section{Abstract}

Background \& Objective: Non-communicable diseases like systemic arterial hypertension (SAH) and dyslipidemia are poorly studied in terms of patient journey aspects. This semi-systematic review provides evidence synthesis for the management of SAH and dyslipidemia in Brazil and also discusses challenges faced by patients at the local level along with a suggested care approach by local experts.

Methods: A semi-systematic review using both structured literature databases (Embase and Medline) and unstructured scientific records (WHO, IPD, MOH and Google) on hypertension and dyslipidemia in the English language from 2010-2019 was performed by reviewers. After two-level screening based on pre-defined criteria, patient journey touchpoints and prevalence information were extracted from the included articles. Data gaps were bridged through the insights of local experts.

Conclusion: Limited patient education, regional disease distribution, and treatment allocation, along with limited resources for diagnosis and treatment are the key challenges. To improve overall patient journey considering critical touchpoints, timely and strict adoption of pharmacological treatment guidelines, campaigns for increased patient literacy about healthy diet and lifestyle modification, about the importance of self-reporting for early disease diagnosis, and benefits of treatment adherence are strongly recommended. Also, it is suggested to ensure the availability of skilled resources through continued education to render quality care to cardiovascular patients in Brazil.

\section{Introduction}

Cardiovascular diseases (CVDs) are the major cause of death worldwide with an estimated global mortality of 17.9 million in 2016,[1] which is expected to increase to 23.6 million in 2030.[2] Systemic arterial hypertension (SAH) and dyslipidemia are the primary risk factors for cardiovascular complications.[3] SAH is a multi-system complex disease with an estimated prevalence of $37.3 \%$ and $22.9 \%$ in developing and industrialized countries, respectively,[4] and accounts for $45 \%$ of cardiac deaths and $51 \%$ of stroke-related deaths. [5] Dyslipidemia is characterized by the presence of elevated blood low-density lipoprotein cholesterol (LDL-C) or high triglycerides with or without low levels of high-density lipoprotein cholesterol (HDL-C).[6] High LDL-C levels are an independent risk factor for coronary artery disease[7]; elevated LDL-C levels of $\geq 100 \mathrm{mg} / \mathrm{dL}$ increased the risk of CVD-related death by $30 \%$, whereas LDL-C levels $\geq 130 \mathrm{mg} / \mathrm{dL}$ resulted in $>50 \%$ increased risk in coronary heart disease-related death.[8] Raised cholesterol causes nearly $33 \%$ of global ischemic heart diseases accounting for nearly 2.6 million deaths every year.[9]

Studies in Brazil have shown a nearly $30 \%$ prevalence of hypertension in the adult population, corresponding to nearly 36 million patients[10], and the prevalence of dyslipidemia in some regions in Brazil is nearly 32.7\%.[11] Data on prevalence show that diagnosis of dyslipidemia is more frequent in women (15.1\%) compared with men (9.7\%).[12] A similar pattern was observed through Vigitel (a phone health survey conducted by the Brazilian Ministry of Health), where the prevalence of dyslipidemia in women and men was $25.9 \%$ and $18.8 \%$, respectively. [13] Regarding age, hypertension is more common in individuals of age 50-59 years than in those who are 20-29 years old,[3] and a higher prevalence of elevated cholesterol has been reported in the Brazilian population aged 45 years or older and with low education.[11]

The coexistence of dyslipidemia and hypertension has been reported in $50-80 \%$ of patients and their synergistic effects result in an increased risk of CVDs, which is greater than the sum of individual risks.[[14][15] Although the causal association is yet to be proven, epidemiological studies have shown that low HDL-C levels are associated with a twofold increase in fatal CVD risk.[16]

Despite the major contribution of SAH and dyslipidemia in cardiovascular morbidity and mortality, data regarding their nationwide prevalence, awareness, screening, diagnosis, treatment, adherence, and control are scarce. Most of the studies in the Brazilian population are region-specific, thus limiting their applicability to the population of the entire country. For non-communicable chronic diseases (NCDs), an understanding of the patient journey from a patient's perspective can help improve healthcare systems to address the unmet needs of patients as well as increase patient participation and disease management.[17] Given the sparse information on screening, diagnosis, and treatment of SAH and dyslipidemia in Brazil, the present review aims to provide a situational analysis of the current management of these conditions and to identify challenges in care delivery at various levels to help strategize the optimization of the patient journey as a whole.

\section{Methods}

\subsection{Search strategy and selection criteria}

A structured search using Medline, Embase followed by unstructured search using resources like World Health Organization (WHO), Ministry of Health (MOH) websites, Incidence and Prevalence Database (IPD) and Google was performed from Dec 10, 2019 by reviewer 1. The search terms included words related to patient journey touchpoints, clinical condition (SAH and Dyslipidemia) as well as context (Brazil). The detailed search strategy is given in appendix. Original research, systematic review, meta-analyses articles in English from 2010-2019 were 
retrieved. After duplicate removal, first-level screening was done by reviewer 1 based on relevance. Non-relevant records were excluded during level -2 screening by reviewer 2 based on exclusion criteria, that included age $<18$ years, case reports, letter to editors, articles with no patient journey data (prevalence, awareness, screening, diagnosis, treatment, adherence, and control), written in a non-English language, articles with non-representative study sample or study from other than Brazil region.[18] Also, this review excluded studies with specific groups of patients (elderly, pregnant women, co-morbidities). Any disagreements about the inclusion of any record were resolved through discussion between both reviewers. An additional file shows detailed search strategy [see Additional file 1].

Hypertension was defined as systolic blood pressure (BP) $\geq 140 \mathrm{~mm} \mathrm{Hg}$ and/or diastolic BP $\geq 90 \mathrm{~mm}$ Hg.[19] Dyslipidemia was defined as total cholesterol of $\geq 5 \mathrm{mmol} / \mathrm{L}$ or $\geq 200 \mathrm{mg} / \mathrm{dL}$.[20] Disease control was defined as the proportion of patients achieving a target BP of $\leq$ $140 / 90 \mathrm{~mm} \mathrm{Hg}$ or cholesterol of $\leq 5 \mathrm{mmol} / \mathrm{L}$ or $\leq 200 \mathrm{mg} / \mathrm{dL}$ with treatment.

\subsection{Data extraction and synthesis}

Data extraction included study year, sample size, prevalence, awareness, screening, diagnosis, treatment, adherence, and control data points (in percentages) and associated challenges from both patient's and health system's angle. Data gaps were addressed by supplementing with local studies and anecdotal data from local experts. Quantitative data for prevalence, awareness, screening, diagnosis, treatment, adherence, and control were synthesized through weighted mean or simple mean.

\section{Results}

\subsection{Study selection}

Overall, 2428 articles were retrieved from the structured search and 4 were obtained from the unstructured search. After the abstract screening, 103 articles were identified as relevant. Six articles were obtained from external experts. These were manually screened for inclusion and exclusion criteria, and finally, 16 full-text articles and one anecdotal evidence were included. The characteristics of the included articles/records and PRISMA flow diagrams for SAH and dyslipidemia are given in Table 1, Fig. 1, and Fig. 2, respectively. 
Table 1

Characteristics of included studies

\begin{tabular}{|c|c|c|c|c|c|c|c|c|c|c|}
\hline $\begin{array}{l}\text { S. } \\
\text { No. }\end{array}$ & Author & Year & Sample Size & $\begin{array}{l}\text { Prevalence } \\
\text { (\%) }\end{array}$ & $\begin{array}{l}\text { Awareness } \\
\text { (\%) }\end{array}$ & $\begin{array}{l}\text { Screening } \\
(\%)\end{array}$ & $\begin{array}{l}\text { Diagnosis } \\
\text { (\%) }\end{array}$ & $\begin{array}{l}\text { Treatment } \\
\text { (\%) }\end{array}$ & $\begin{array}{l}\text { Adherence } \\
\text { (\%) }\end{array}$ & $\begin{array}{l}\text { Control } \\
\text { (\%) }\end{array}$ \\
\hline \multicolumn{11}{|c|}{ Systemic Arterial Hypertension } \\
\hline 1 & $\begin{array}{l}\text { Lamelas } \\
\text { [21] }\end{array}$ & 2019 & 5553 & 52.5 & 64.7 & & & 62.7 & & 23.4 \\
\hline 2 & Mendis [22] & 2014 & $20,27,64,000$ & 23 & & & & & & \\
\hline 3 & Malta [11] & 2018 & 60202 & 32.3 & 21.4 & & & & & \\
\hline 4 & Picon [23] & 2012 & 122018 & 28.7 & 20.6 & & & & & \\
\hline 5 & $\begin{array}{l}\text { Malachias } \\
\text { [24] }\end{array}$ & 2016 & & 32.5 & & & & $\begin{array}{l}11.4- \\
77.5\end{array}$ & & $\begin{array}{l}10.1- \\
35.5\end{array}$ \\
\hline 6 & Lotufo [25] & 2015 & & & & 97 & & 81.4 & & \\
\hline 7 & $\begin{array}{l}\text { Barbosa } \\
{[26]}\end{array}$ & 2019 & 7260 & 47 & & & & & & 60 \\
\hline 8 & $\begin{array}{l}\text { Vigitel } \\
\text { Brazil } 2018 \\
\text { [27] }\end{array}$ & 2018 & 52395 & & & & 24.7 & & & \\
\hline 9 & $\begin{array}{l}\text { Regional } \\
\text { Experts }\end{array}$ & & & & & & & & 50 & \\
\hline \multicolumn{11}{|c|}{ Dyslipidemia } \\
\hline $\begin{array}{l}\text { S. } \\
\text { No. }\end{array}$ & Author & Year & Sample Size & $\begin{array}{l}\text { Prevalence } \\
\text { (\%) }\end{array}$ & $\begin{array}{l}\text { Awareness } \\
\text { (\%) }\end{array}$ & $\begin{array}{l}\text { Screening } \\
(\%)\end{array}$ & $\begin{array}{l}\text { Diagnosis } \\
(\%)\end{array}$ & $\begin{array}{l}\text { Treatment } \\
\text { (\%) }\end{array}$ & $\begin{array}{l}\text { Adherence } \\
\text { (\%) }\end{array}$ & $\begin{array}{l}\text { Control } \\
\text { (\%) }\end{array}$ \\
\hline 1 & Malta [11] & 2019 & 8534 & 32.7 & & & & & & \\
\hline 2 & Borgo [28] & 2019 & 318 & 42.3 & & & & & & \\
\hline 3 & $\begin{array}{l}\text { Goncalves } \\
\text { [29] }\end{array}$ & 2019 & 60202 & & 11.03 & & 12.5 & & & \\
\hline 4 & $\begin{array}{l}\text { Vigitel } \\
\text { Brazil } 2016 \\
\text { [13] }\end{array}$ & 2016 & 53210 & & 22.6 & & & & & \\
\hline 5 & Lotufo [12] & 2017 & 60202 & & & 55.4 & 12.5 & & & \\
\hline 6 & $\begin{array}{l}\text { do } \\
\text { Nascimento } \\
\text { [30] }\end{array}$ & 2018 & 8803 & & & & & 24.6 & 93.5 & \\
\hline 7 & $\begin{array}{l}\text { Faria Neto } \\
\text { [31] }\end{array}$ & 2019 & 1451 & & & & & & & 29.8 \\
\hline 8 & Lotufo [32] & 2016 & 15105 & 45.5 & $58.1^{\#}$ & & & 42.3 & & 58.3 \\
\hline
\end{tabular}

\subsection{Summary of findings}

The prevalence of hypertension in Brazil was $23 \%,[11,22,21,23,24,26]$ and a low patient awareness (22.2\%) was observed on SAH.[11, 21, 23] Strategies for screening hypertension were found to be effective, and $97 \%$ of the population was screened[25]; however, the patient diagnosis was suboptimal (24.7\%).[27] Most of the patients diagnosed with hypertension followed pharmacological treatment (62.9\%);[21, $24,25]$ however, only half of them $(50 \%)$ adhered to the treatment, as opined by local experts. As a result, the target outcomes were achieved by only one-third of the patients $(32.7 \%)$. [21, 24, 26] Dyslipidemia was observed in $40.8 \%$ of the population[11, 28, 32] and awareness regarding the disease was found in a larger proportion (58.1\%) than in SAH.[32] Although more than half of the patient population was screened (55.4\%)[12], only a small number of patients received proper diagnosis $(12.5 \%),[12,29]$ thus suggesting the need for expanding the reach of diagnostic techniques. The percentage of patients receiving treatment was low $(30.0 \%),[30,32]$ which may reflect the challenges in 
providing equitable access to dyslipidemia treatment for patients across the country, or the lack of prescription by the physicians who overlook the importance of lipids control. Maybe as a result, the proportion of patients who achieve the cholesterol levels recommended by the Brazilian Society of Cardiology[32] is low (29.8\%).[33] A previous study described overall cholesterol control rates around 58\%, but they observed that the control of LDL-C was markedly lower in those patients with higher risk (9.4\%).[29] Only one of the retrieved studies provided adherence data regarding statin use and reported it to be above $90 \%$. The authors felt like this high rate could have been overestimated because it was a self-reported survey and the question regarded only the week before the appointment.[31] Overall, patients with hypertension had a better level of screening, diagnosis, and treatment than patients with dyslipidemia. However, awareness and adherence were found to be higher in patients with dyslipidemia compared to those in patients with hypertension. The graphical visualization of the summary of findings can be seen in Fig. 3.

\section{Discussion}

The Brazilian healthcare system is segmented into public and private subsystems. The public subsystem named the Sistema Único de Saúde (SUS) provides free and universal healthcare access to all citizens, covering nearly $75 \%$ of the population. Most of the patients get treated by general practitioners at first and are unable to get cardiology consultations unless there are any established coronary diseases, core comorbidities or secondary complications. On the other hand, in the private subsystem, the patient can go directly to the specialist they want to see irrespective of their health condition. Approximately $30 \%$ of the Brazilian CVD patients directly visit private care specialists because of better access to diagnostic tests, quicker appointments, and better customized care. The approach to treatment in public and private institutions is also different. For example, risk factors control is limited in the case of primary care, general practitioners, or family physicians. Some studies worldwide suggest that private specialist clinics have been more successful in delivering care and achieving the recommended goals when treating the patients, and local publications are in line with these observations. [33-37]

\subsection{Challenges with patient journey touchpoints}

Combined results of several studies and awareness campaigns conducted by the Brazilian Society of Cardiology showed that nearly onethird of the Brazilian population is hypertensive and general awareness is low.[38] Low patient awareness could be attributable to low patient education and prevailing social inequalities, which affect access to and use of health services and medications, as well as adherence to medical prescription.[39] In Brazil, nearly half of all CVD-related deaths in patients aged < 65 years are attributable to poverty, social inequalities, and low educational status.[40-42] Furthermore, awareness regarding the benefit of a healthy lifestyle is limited, and we observe the adoption of unhealthy diets, low physical activity, and high consumption of alcohol and tobacco especially in low-income communities. [40] It is important that both patients and health care professionals belonging to the public health system[43, 44] receive continued education and updates from the latest available clinical practice guidelines from the Brazilian Society of Cardiology, and that they understand the importance of adopting the guidelines and achieving the goals in daily practice.

A limited sense of urgency in the Brazilian population for timely diagnosis and management of CVDs due to the asymptomatic nature of the conditions was observed. As a result, although the number of screened patients with SAH and dyslipidemia was high, it did not convert into effective care. Moreover, the diagnosis of complex diseases that require molecular diagnosis, like familial hypercholesterolemia, is hindered by the limited availability of specialized laboratories. [45][46]

The percentage of patients receiving treatment for SAH was higher than that for dyslipidemia. This could be attributable to better screening and diagnosis of SAH and limited access to lipid lowering medications in certain regions in Brazil. Limited access to healthcare and regional variations in treatment protocols further complicates the scenario.

Addressing adherence-related issues is fundamental for reducing CVD-related morbidity and mortality. In Brazil, pharmacological treatment guidelines developed by international or local societies/associations for CVD prevention are not strictly followed. Reasons for low patient adherence in SUS primary healthcare were limited access, forgetfulness, and adverse effects of medicines, with several studies reporting unintentional non-adherence in most patients.[30]

\subsection{Challenges identified in government initiatives}

There are programs run by the Brazilian government ensuring free-of-cost access to selected medications.[47] This initiative works rather well owing to the involvement of drugstore chains; however, there are limitations regarding the type of medications available as part of such programs. Furthermore, there are no specific programs in either public or private health systems to monitor and optimize patient adherence. A few public healthcare professionals in several regions of Brazil visit patients[48] at home to follow up on chronic and genetic diseases, but data about the effectiveness of this initiative are limited.

\subsection{Proposed healthcare model}


The proposed healthcare model for CVD care in Brazil focuses on 3 pillars: patient education, guideline adoption, and overall optimization of the patient journey.

Population-based approaches in awareness campaigns should be prioritized over individual-based approaches for the prevention, detection and control of CVDs, for it is known that early detection may translate into better control. Blood pressure(BP) and cholesterol levels measurements could be made mandatory at issuance places for government documents, like passports, driver's license, marriage certificate, or other security cards, contributing to a substantial increase in screening and awareness.[21] The healthcare providers should explain the importance of routine check-ups and the negative consequences of non-adherence and delayed treatments of SAH and dyslipidemia to the patients. This could help develop a sense of urgency and proactivity, leading to better compliance and adherence to treatment. Also, encouraging the population to adopt healthy lifestyle habits, including healthier diets and exercise programs, along with the guidance about the medications, can help lower the risk of the patients.

Secondly, strategic adoption of up-to-date clinical practice guidelines with customization based on the regional context could enhance healthcare professionals' compliance. Healthcare programs should be designed to align with the needs of the most affected populations, such as the older patients, which may not be the target of current initiatives. Not only medications guidelines should be followed. For example, reinforcing dietary portfolios, such as reduction in sodium intake and the dietary approaches to stop hypertension (DASH) type of diet,[49] should be considered as an early measure with the potential to decrease the progression from prehypertension to hypertension.

The third and most important pillar of our proposed healthcare model is the overall optimization of the patient journey in SAH and dyslipidemia. Non-physician healthcare workers should be trained to screen for the diseases, helping overcome the shortage of physicians in primary care centers. 'Hospital to home' initiative should be followed aiming to improve treatment compliance, resulting in better patient quality of life, and outcomes.[50] This initiative focuses on smooth transitioning from hospitals to homes by providing psychological and medication-related care to patients based on their requirements and has been effective in reducing rehospitalization by as much as $61 \%$ in the high-risk adult population.[51] Besides ensuring adequate treatment from the healthcare system, it is important to provide easy access and availability of antihypertensive and lipid-lowering medications for patients with SAH and dyslipidemia, demanding an active role of pharmacy professionals. Also, technological upgrades of existing medical centers can help improve the management of these diseases. For example, the World Heart Federation recommends point-of-care testing for measuring cholesterol in less developed regions.[52] Hand-held echocardiography in primary care centers should be encouraged over conventional echocardiography as a prioritization tool for patients with heart disease because of its resource-friendliness. As a step forward, integrating echocardiographic tracking and distance interpretation through telemedicine can help resolve the problems of late diagnosis and long queues for patients requiring specialized care.[53] Partnering with academia could help in building up the healthcare workforce capacity and skills at individual, family, and community levels. Clinical outcome analysis should be performed with a patient-centered care delivery focus, with the possible incorporation of new technologies to help facilitate this delivery. Engaging patients in health care decision-making could contribute to integrating personalized care concepts. Lastly, the government could devise innovative financing models comprising funds to healthcare facilities for conducting local surveys regarding patient journey mapping, and also for establishing a universal and sustainable healthcare system. Figure 4 summarizes the challenges and proposed solutions related to CVD patient journey in Brazil.

\section{Conclusion}

The scope of this semi-systematic review was to design the patient journey to devise ways to improve patient awareness and diagnosis for $\mathrm{SAH}$ and dyslipidemia in Brazil. The major challenges to SAH and dyslipidemia management in Brazil included patient education, regional disease distribution and medicament allocation, as well as limited resources for proper diagnosis and treatment. To overcome these, we propose strict adoption of the latest treatment guidelines and intensification of patient awareness campaigns about healthy diet and lifestyle modification, the importance of screening for early disease diagnosis, and the benefits of treatment adherence. Also, optimization of the patient journey could involve the implementation of a multisectoral care delivery model focused on medication adherence, availability of skilled resources to meet local care demands, technological integration, and patient-centric policy initiatives.

\section{List Of Abbreviations}

SAH

systemic arterial hypertension

CVDs

cardiovascular diseases

LDL-C

low-density lipoprotein C 
HDL-C

high-density lipoprotein $\mathrm{C}$

NCDs

non-communicable diseases

WHO

world health organization

$\mathrm{MOH}$

ministry of health

IPD

incidence and prevalence database

BP

blood pressure

SUS

Sistema único de saúde

DASH

dietary approaches to stop hypertension

\section{Declarations}

\section{Ethics approval and Consent to participation}

There was no requirement for the ethics committee's approval for this semi-systematic review on available literature and real-world evidence which did not have direct contact with patients.

\section{Consent for publication}

Not applicable

\section{Availability of data and materials}

The datasets analyzed are available in the bibliographic section. No patient data/file was used in the current study. In addition, data from local experts supporting findings of this study will be available on request from the corresponding author.

\section{Competing interests}

JRF received honoraria for consulting, speaker, or research activities from Aché, Astra Zeneca, Amgen, EMS, Merck, MSD, Novo-Nordisk, Pfizer, PTC therapeutics, and Sanofi/Regeneron. He is a recipient of a scholarship from the Conselho Nacional de Pesquisa e Desenvolvimento Tecnologico (CNPq) process \# 314145/2018-4. RDS received honoraria for consulting, speaker, or research activities from Abbott, Aché, Astra Zeneca, Amgen, EMS, Esperion, GETZ pharma, Kowa, Libbs, Merck, MSD, Novo-Nordisk, Novartis, Pfizer, PTC Therapeutics, and Sanofi/Regeneron. He is a recipient of a scholarship from the Conselho Nacional de Pesquisa e Desenvolvimento Tecnologico (CNPq) process \# 303734/2018-3, Brazil. LFV, ENS and CRY are employees of Pfizer Upjohn.

\section{Funding}

This study was funded by Upjohn - a legacy division of Pfizer.

\section{Authors' contributions}

CRY, LFV, and ENS designed the research, synthesized the findings, validated the data, drafted, and reviewed the manuscript. RDS and JRF validated the data and performed manuscript drafting and reviewing. All the authors read and approved the final manuscript.

\section{Acknowledgments}


We acknowledge the experts who provided insights for bridging the data gaps. This study was funded by Upjohn - a legacy division of Pfizer. The medical writing support was provided by Kapil Khambholja; the Indegene MW team. The support provided by the independent reviewers Utsavi Samel from Viatris and Aditi Karmarkar from Upjohn - A Pfizer division is deeply acknowledged. We also thank Kaveri Sidhu from Upjohn - A Pfizer division for critically reviewing the draft.

\section{References}

1. Cardiovascular diseases (CVDs). https://www.who.int/news-room/fact-sheets/detail/cardiovascular-diseases-(cvds). Accessed 29 Jan 2021.

2. Benjamin EJ, Muntner P, Alonso A, Bittencourt MS, Callaway CW, Carson AP, et al. Heart Disease and Stroke Statistics-2019 Update: A Report From the American Heart Association. Circulation. 2019;139. doi:10.1161/CIR.0000000000000659.

3. Radovanovic CAT, dos Santos LA, Carvalho MD de B, Marcon SS. Arterial Hypertension and other risk factors associated with cardiovascular diseases among adults1. Rev Lat Am Enfermagem. 2014;22:547-53.

4. Kearney PM, Whelton M, Reynolds K, Muntner P, Whelton PK, He J. Global burden of hypertension: analysis of worldwide data. The Lancet. 2005;365:217-23.

5. Lim SS, Vos T, Flaxman AD, Danaei G, Shibuya K, Adair-Rohani H, et al. A comparative risk assessment of burden of disease and injury attributable to 67 risk factors and risk factor clusters in 21 regions, 1990-2010: a systematic analysis for the Global Burden of Disease Study 2010. The Lancet. 2012;380:2224-60.

6. Adiels Martin, Olofsson Sven-Olof, Taskinen Marja-Riitta, Borén Jan. Overproduction of Very Low-Density Lipoproteins Is the Hallmark of the Dyslipidemia in the Metabolic Syndrome. Arterioscler Thromb Vasc Biol. 2008;28:1225-36.

7. Karalis DG. Intensive Lowering of Low-Density Lipoprotein Cholesterol Levels for Primary Prevention of Coronary Artery Disease. Mayo Clin Proc. 2009;84:345-52.

8. Abdullah SM, Defina LF, Leonard D, Barlow CE, Radford NB, Willis BL, et al. Long-Term Association of Low-Density Lipoprotein Cholesterol With Cardiovascular Mortality in Individuals at Low 10-Year Risk of Atherosclerotic Cardiovascular Disease. Circulation. 2018;138:2315-25.

9. World Health Organization, editor. Global health risks: mortality and burden of disease attributable to selected major risks. Geneva, Switzerland: World Health Organization; 2009.

10. Santiago ERC, Diniz A da S, Oliveira JS, Leal VS, de Andrade MIS, de Lira PIC. Prevalence of Systemic Arterial Hypertension and Associated Factors Among Adults from the Semi-Arid Region of Pernambuco, Brazil. Arq Bras Cardiol. 2019;113:687-95.

11. Malta DC, Szwarcwald CL, Machado ÍE, Pereira CA, Figueiredo AW, Sá ACMGN de, et al. Prevalência de colesterol total e frações alterados na população adulta brasileira: Pesquisa Nacional de Saúde. Rev Bras Epidemiol. 2019;22 suppl 2:E190005.SUPL.2.

12. Lotufo PA, Santos RD, Sposito AC, Bertolami M, Rocha-Faria Neto J, Izar MC, et al. Self-Reported High-Cholesterol Prevalence in the Brazilian Population: Analysis of the 2013 National Health Survey. Arq Bras Cardiol. 2017;108:411-6.

13. Vigitel Brasil 2016: vigilância de fatores de risco e proteção para doenças crônicas por inquérito telefônico: estimativas sobre frequência e distribuição sociodemográfica de fatores de risco e proteção para doenças crônicas nas capitais dos 26 estados brasileiros e no Distrito Federal em 2016. 2016;:160.

14. McEvoy JW, Whelton Seamus P, Blumenthal RS. 38 - Dyslipidemia. In: Bakris GL, Sorrentino MJ, editors. Hypertension: A Companion to Braunwald's Heart Disease (Third Edition). Elsevier; 2018. p. 353-60. doi:10.1016/B978-0-323-42973-3.00038-X.

15. O’Meara JG, Kardia SLR, Armon JJ, Brown CA, Boerwinkle E, Turner ST. Ethnic and Sex Differences in the Prevalence, Treatment, and Control of Dyslipidemia Among Hypertensive Adults in the GENOA Study. Arch Intern Med. 2004;164:1313-8.

16. Weverling-Rijnsburger AWE, Jonkers IJAM, van Exel E, Gussekloo J, Westendorp RGJ. High-density vs low-density lipoprotein cholesterol as the risk factor for coronary artery disease and stroke in old age. Arch Intern Med. 2003;163:1549-54.

17. Devi R, Kanitkar K, Narendhar R, Sehmi K, Subramaniam K. A Narrative Review of the Patient Journey Through the Lens of Noncommunicable Diseases in Low- and Middle-Income Countries. Adv Ther. 2020. doi:10.1007/s12325-020-01519-3.

18. Bharatan T, Devi R, Huang P-H, Javed A, Jeffers B, Lansberg P, et al. A methodology for mapping the patient journey for noncommunicable diseases in low- and middle-income countries. $J$ Healthc Leadersh.

19. Kanegae H, Oikawa T, Okawara Y, Hoshide S, Kario K. Which blood pressure measurement, systolic or diastolic, better predicts future hypertension in normotensive young adults? J Clin Hypertens Greenwich Conn. 2017;19:603-10.

20. Liu G, Shepherd J, Rane P, Zhao Z, Bailey H, Williams N, et al. Characteristics of patients with dyslipidemia treated in routine care setting in China. J Drug Assess. 2019;8:192-8. 
21. Lamelas P, Diaz R, Orlandini A, Avezum A, Oliveira G, Mattos A, et al. Prevalence, awareness, treatment and control of hypertension in rural and urban communities in Latin American countries. J Hypertens. 2019;37:1813-21.

22. Mendis S, World Health Organization. Global status report on noncommunicable diseases 2014. 2014.

23. Picon RV, Fuchs FD, Moreira LB, Riegel G, Fuchs SC. Trends in Prevalence of Hypertension in Brazil: A Systematic Review with MetaAnalysis. PLOS ONE. 2012;7:e48255.

24. Malachias MVB, Gomes M a. M, Nobre F, Alessi A, Feitosa AD, Coelho EB, et al. 7th Brazilian Guideline of Arterial Hypertension: Chap. 2 Diagnosis and Classification. Arq Bras Cardiol. 2016;107:7-13.

25. Lotufo PA, Lotufo PA. Cardiovascular diseases in Brazil: premature mortality, risk factors and priorities for action. Comments on the preliminary results from the Brazilian National Health Survey (PNS), 2013. Sao Paulo Med J. 2015;133:69-72.

26. Barbosa E, Eibel B, Brandão AA, Feitosa ADM, Miranda RD, Kobeissi E, et al. May Measurement Month 2017: Brazilian results-Americas. Eur Heart J Suppl. 2019;21 Supplement_D:D25-7.

27. vigitel-brasil-2018.pdf. https://portalarquivos2.saude.gov.br/images/pdf/2019/julho/25/vigitel-brasil-2018.pdf. Accessed 28 Jan 2021.

28. Borgo MV, Pimentel EB, Baldo MP, Souza JB de, Malta DC, Mill JG, et al. Prevalence of cardiovascular risk factors in the population of Vitória according to data from VIGITEL and the National Health Interview Survey of 2013. Rev Bras Epidemiol. $2019 ; 22$. doi:10.1590/1980-549720190015.

29. Gonçalves RPF, Haikal DS, Freitas MI de F, Machado ÍE, Malta DC. Diagnóstico médico autorreferido de doença cardíaca e fatores de risco associados: Pesquisa Nacional de Saúde. Rev Bras Epidemiol. 2019;22 suppl 2:E190016.SUPL.2.

30. Nascimento RCRM do, Jr AAG, Alvares J, Gomes IC, Godman B, Bennie M, et al. Statin use in Brazil: findings and implications. Curr Med Res Opin. 2018;34:1809-17.

31. Faria Neto JR, Andre B, Erbano L, Baena CP, Olandoski M. Achieving lipid targets in patients at high cardiovascular risk in public healthcare - real world data from Curitiba. In: Arquivos Brasileiros de Cardiologia. Sociedade Brasileira de Cardiologia - SBC; 2019. p. 1279.

32. Lotufo PA, Santos RD, Figueiredo RM, Pereira AC, Mill JG, Alvim SM, et al. Prevalence, awareness, treatment, and control of high lowdensity lipoprotein cholesterol in Brazil: Baseline of the Brazilian Longitudinal Study of Adult Health (ELSA-Brasil). J Clin Lipidol. 2016;10:568-76.

33. Ho PM, Masoudi FA, Peterson ED, Grunwald GK, Sales AE, Hammermeister KE, et al. Cardiology management improves secondary prevention measures among patients with coronary artery disease. J Am Coll Cardiol. 2004;43:1517-23.

34. New JP, Mason JM, Freemantle N, Teasdale S, Wong LM, Bruce NJ, et al. Specialist nurse-led intervention to treat and control hypertension and hyperlipidemia in diabetes (SPLINT): a randomized controlled trial. Diabetes Care. 2003;26:2250-5.

35. Ltd BPGL and RPC. Nurse led clinics controlled hypertension and hyperlipidaemia better than usual care in diabetes. Evid Based Nurs. 2004;7:48-48.

36. Tran AT, Bakke Å, Berg TJ, Gjelsvik B, Mdala I, Nøkleby K, et al. Are general practitioners characteristics associated with the quality of type 2 diabetes care in general practice? Results from the Norwegian ROSA4 study from 2014. Scand J Prim Health Care. 2018;36:170-9.

37. Singer Gregory M., Izhar Munavvar, Black Henry R. Goal-Oriented Hypertension Management. Hypertension. 2002;40:464-9.

38. Précoma DB, Oliveira GMM de, Simão AF, Dutra OP, Coelho OR, Izar MC de O, et al. Updated Cardiovascular Prevention Guideline of the Brazilian Society of Cardiology - 2019. Arq Bras Cardiol. 2019;113:787-891.

39. Demoner MS, Ramos ER de P, Pereira ER. Factors associated with adherence to antihypertensive treatment in a primary care unit. Acta Paul Enferm. 2012;25:27-34.

40. Pampel FC, Krueger PM, Denney JT. Socioeconomic Disparities in Health Behaviors. Annu Rev Sociol. 2010;36:349-70.

41. Bassanesi SL, Azambuja MI, Achutti A. Premature mortality due to cardiovascular disease and social inequalities in Porto Alegre: from evidence to action. Arq Bras Cardiol. 2008;90:370-9.

42. Polanczyk CA, Ribeiro JP. Coronary artery disease in Brazil: contemporary management and future perspectives. Heart Br Card Soc. 2009;95:870-6.

43. Oliveira PR de, Guerra M, Gomes A de O, Martins AL. Public-private relation in the Brazilian policy of tertiary care for cardiovascular conditions. Rev Adm Pública. 2019;53:753-68.

44. Ribeiro ALP, Duncan BB, Brant LCC, Lotufo PA, Mill JG, Barreto SM. Cardiovascular Health in Brazil: Trends and Perspectives. Circulation. 2016;133:422-33.

45. de Quadros TMB, Gordia AP, da Silva RCR, Silva LR. Predictive capacity of anthropometric indicators for dyslipidemia screening in children and adolescents. J Pediatr (Rio J). 2015;91:455-63. 
46. Santos RD, Frauches TS, Chacra APM. Cascade Screening in Familial Hypercholesterolemia: Advancing Forward. J Atheroscler Thromb. 2015;22:869-80.

47. Costa KS, Tavares NUL, Mengue SS, Pereira MA, Malta DC, Silva Júnior JB da, et al. Obtaining drugs for hypertension and diabetes through the Brazilian People's Pharmacy Program: results of the National Health Survey, 2013. Epidemiol E Serviços Saúde. 2016;25:3344.

48. Andrade MV, Noronha K, Cardoso CS, Oliveira CDL, Calazans JA, Souza MN, et al. Challenges and lessons from a primary care intervention in a Brazilian municipality. Rev Saúde Pública. 2019;53. doi:10.11606/s1518-8787.2019053000457.

49. Sacks FM, Svetkey LP, Vollmer WM, Appel LJ, Bray GA, Harsha D, et al. Effects on blood pressure of reduced dietary sodium and the Dietary Approaches to Stop Hypertension (DASH) diet. DASH-Sodium Collaborative Research Group. N Engl J Med. 2001;344:3-10.

50. Jr NWW. Hospital to Home Initiative - Reviewing the Goals and Challenges. J - Hosp Home Initiat - Rev Goals Chall. 2011. https://www.uscjournal.com/articles/hospital-home-initiative-reviewing. Accessed 29 Jan 2021.

51. Watkins L, Hall C, Kring D. Hospital to home: a transition program for frail older adults. Prof Case Manag. 2012;17:117-23; quiz 124-5.

52. Cholesterol. CVD Roadmaps. https://www.world-heart-federation.org/cvd-roadmaps/whf-global-roadmaps/cholesterol/. Accessed 29 Jan 2021.

53. Rastreamento ecocardiográfico com interpretação à distância via telemedicina como ferramenta de priorização na Atenção Primária: dados do estudo PROVAR+. lats. https://iats.com.br/resenha/rastreamento-ecocardiografico-com-interpretacao-a-distancia-viatelemedicina-como-ferramenta-de-priorizacao-na-atencao-primaria-dados-do-estudo-provar/. Accessed 29 Jan 2021.

\section{Figures}

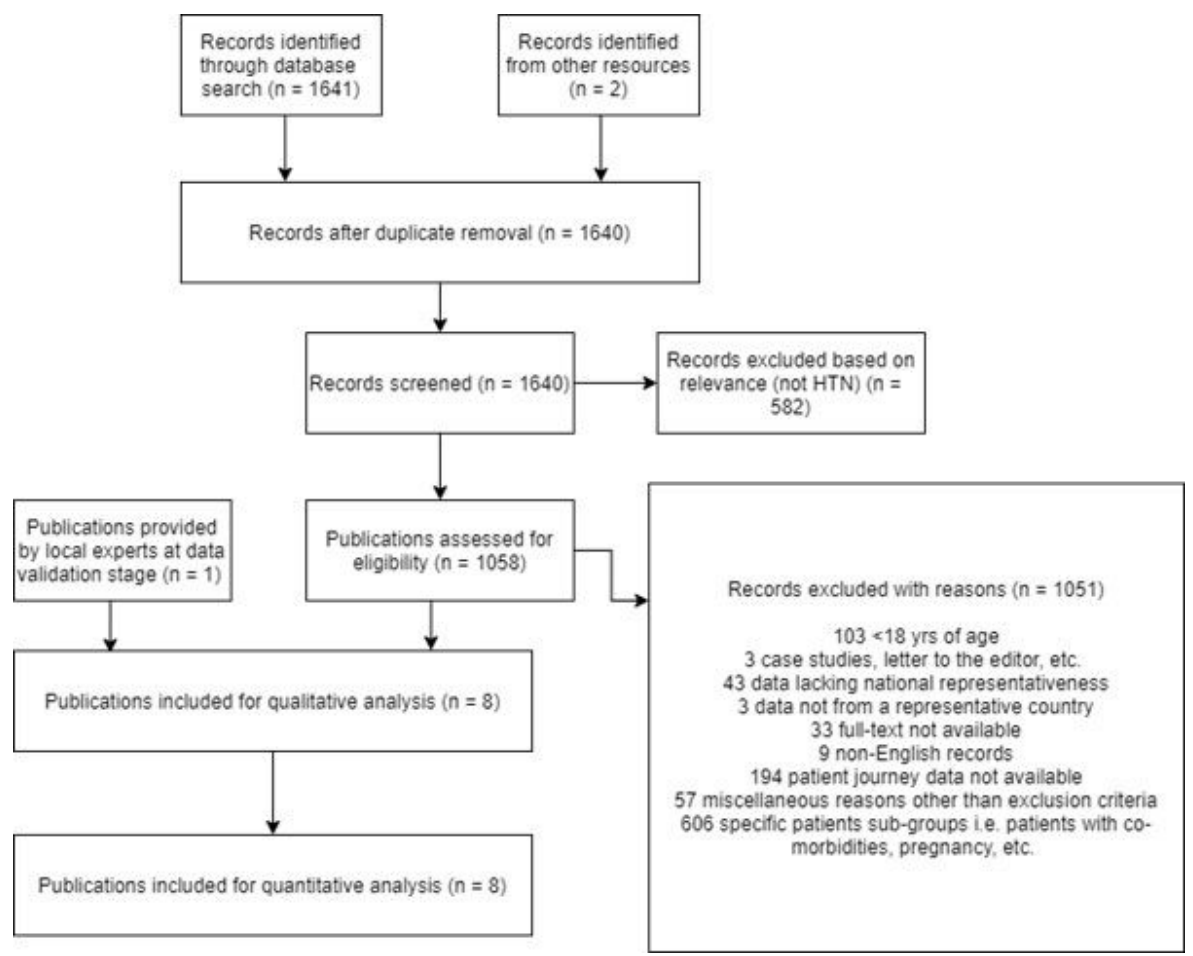

\section{Figure 1}

PRISMA flow diagram for systemic arterial hypertension in Brazil 


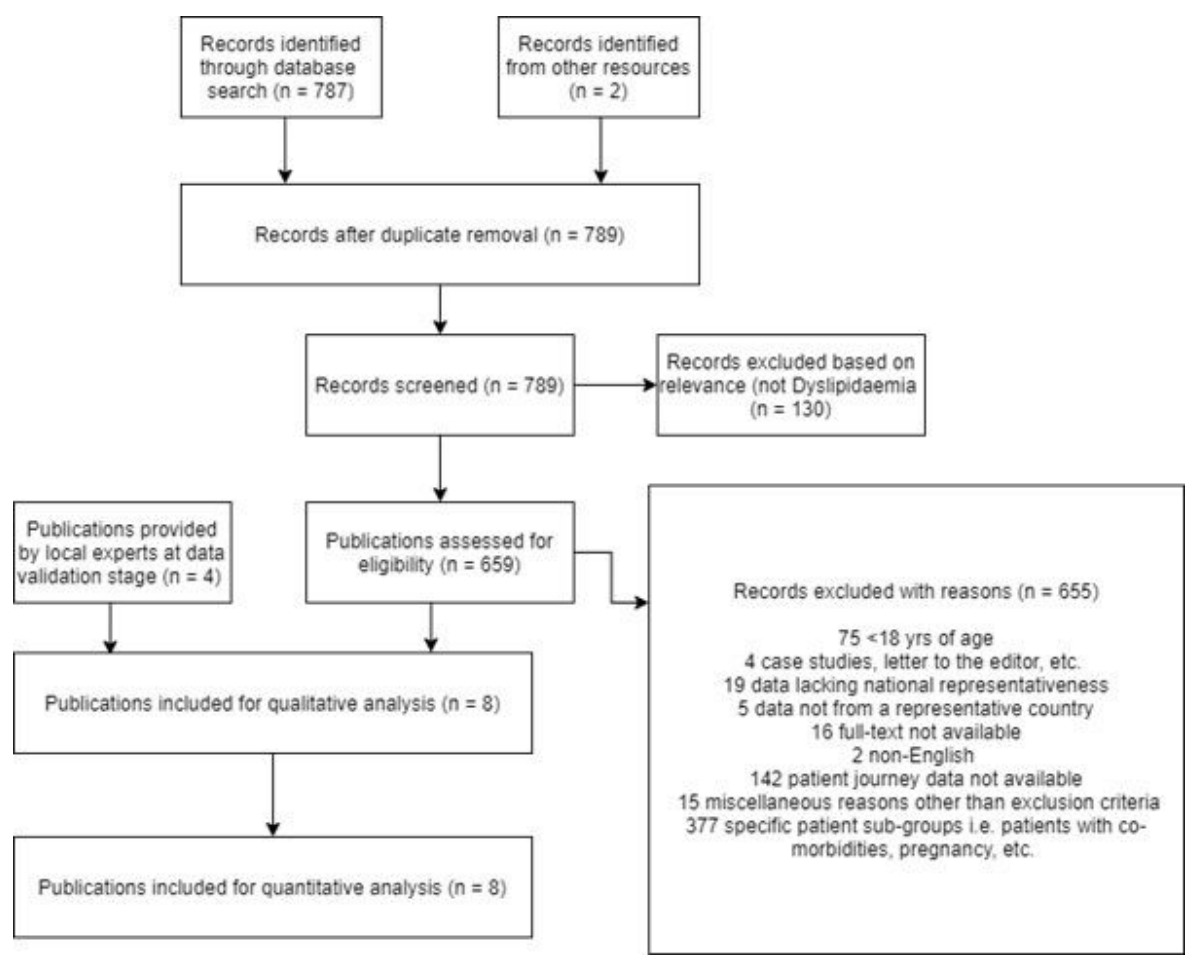

Figure 2

PRISMA flow diagram for dyslipidemia in Brazil

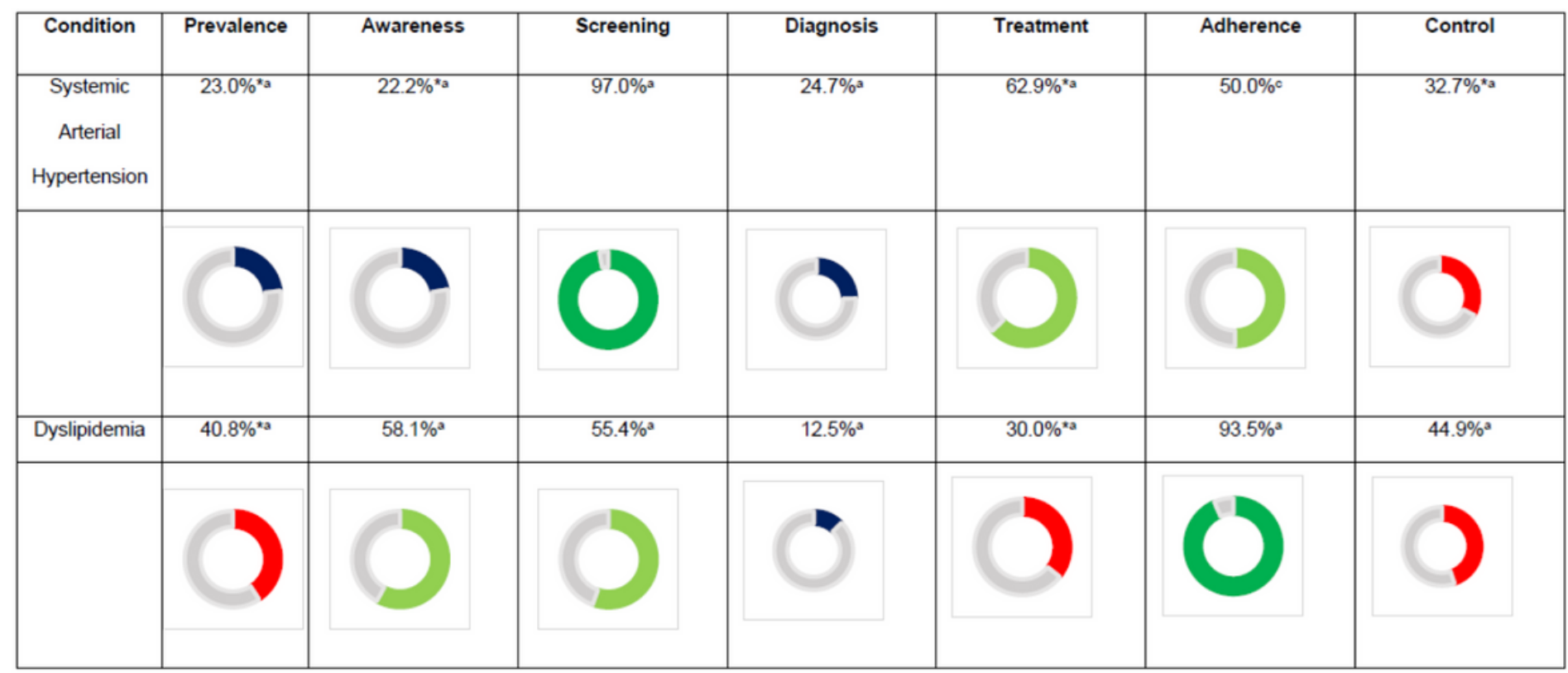

*Weighted average. ; a Peer-reviewed publication.; ${ }^{b}$ Scientific literature + expert opinion.; ${ }^{\circ}$ Expert opinion only

Here navy blue, red, light green, and dark green colored doughnuts are indicative of percentage ranges $\leq 25 \%, 25 \%-50 \%, 50 \%-75 \%$, and $\geq 75 \%$, respectively.

Health literacy: $68 \%^{2}$

\section{Figure 3}

Summary of findings from the included studies on hypertension and dyslipidemia in Brazil. *Weighted average; aPeer-reviewed publication; bScientific literature + expert opinion; cExpert opinion only. Here navy blue, red, light green, and dark green colored doughnuts are indicative of percentage ranges $<25 \%, 25 \%-50 \%, 50 \%-75 \%$, and $>75 \%$, respectively. Health literacy: $68 \%$ a 

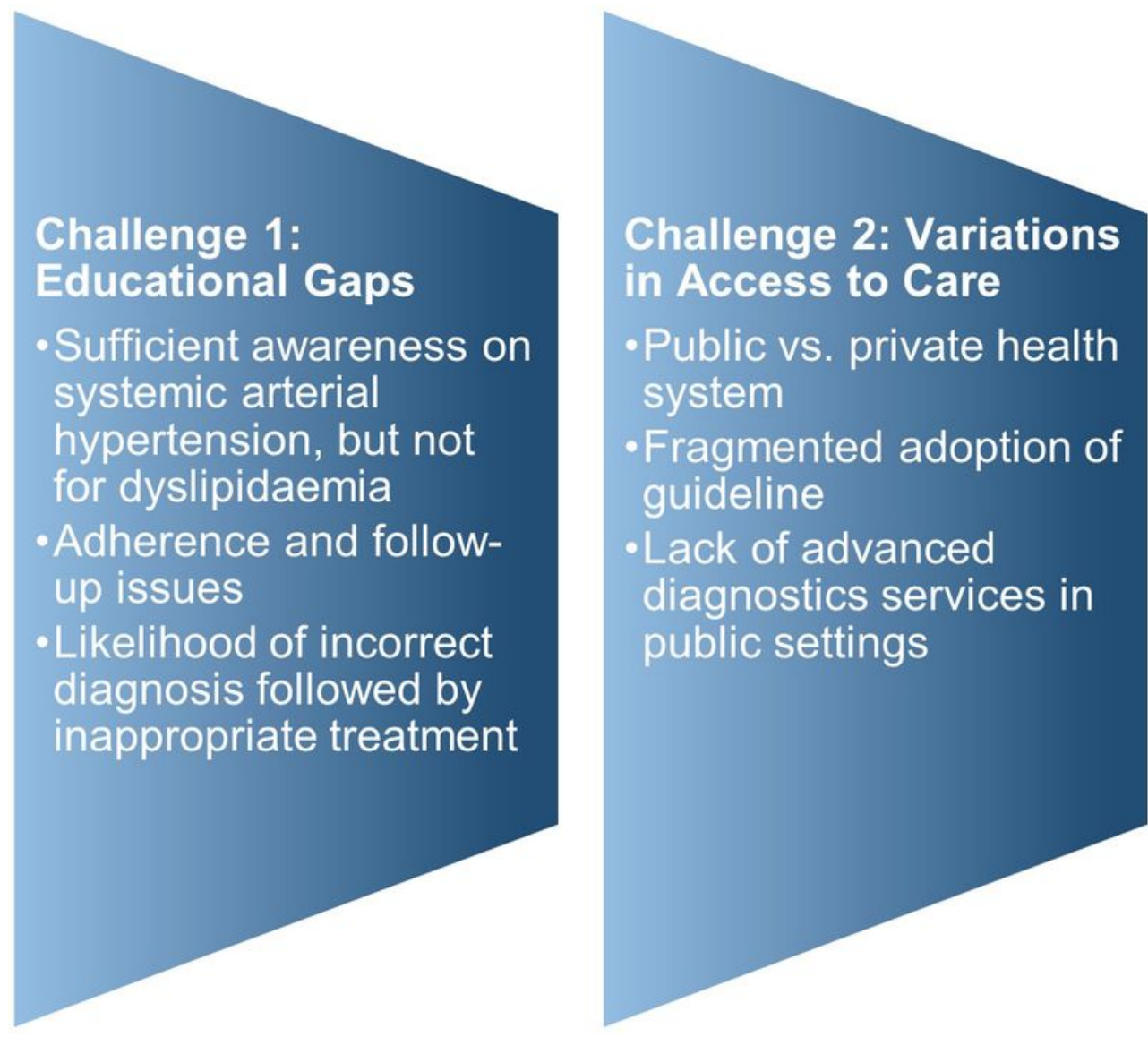

Solution: Patient Journey

Optimisation

-Multisectoral approach for care

- "Hospital to Home"

initiative for treatment compliance

- Easier access to care

- Availability of antihypertensives and lipid-lowering drugs to the right patient on right time

- Technological upgrade of existing diagnositic centres

\section{Figure 4}

Key patient journey challenges and proposed solutions for patients with cardiovascular diseases in Brazil

\section{Supplementary Files}

This is a list of supplementary files associated with this preprint. Click to download.

- Additionalfile1.docx 